\title{
Analysis of the relationship between periodontitis and osteoporosis/ fractures: a cross-sectional study
}

Seok-Jin Hong ${ }^{1,2}$, Byoung-Eun Yang ${ }^{1,3}$, Dae-Myoung Yoo ${ }^{4}$, Sung-Jae Kim ${ }^{5}$, Hyo-Geun Choi ${ }^{1,4,6^{*+}}$ and Soo-Hwan Byun ${ }^{1,3^{*}+}$

\begin{abstract}
Background: Chronic periodontitis is a multifactorial inflammatory disease resulting in patients exhibiting high levels of inflammatory factors causing systemic inflammatory bone destruction that may lead to osteoporosis development. The association between periodontitis and osteoporosis has been documented; however, the findings remain unclear. This study aimed to identify the association between periodontitis and osteoporosis using a cross-sectional study design and Korean Genome and Epidemiology Study (KoGES) health examinee data.
\end{abstract}

Methods: This cross-sectional study used epidemiological data from the KoGES during 2004-2016. Of 125,324 participants (age, 40-79 years), 9969 with periodontitis and 115,332 controls (without periodontitis) were selected. We analyzed the history of osteoporosis and fractures of all participants. All participants were examined according to age, sex, income group, obesity, smoking habits, alcohol consumption, and food intake. To analyze the odds ratio (OR) of periodontitis for those with osteoporosis and fractures, a logistic regression model was used.

Results: The adjusted odds ratio (aOR) of periodontitis for osteoporosis was 2.16 (95\% confidence interval [Cl], $2.01-2.31 ; P<0.001)$. The aOR of periodontitis for any fracture was $1.54(95 \% \mathrm{Cl} 1.46-1.62 ; P<0.001)$.

Conclusion: Osteoporosis and fractures are associated with periodontitis. Performing regular oral hygiene and examinations of bone mineral density are recommended to prevent aggravation of osteoporosis and periodontitis.

Keywords: Periodontitis, Osteoporosis, Fracture, Systemic inflammation

\section{Background}

Periodontitis is a multifactorial inflammatory disease [1], and is the one of the most prevalent diseases involving the loss of periodontal tissues [2]. Periodontal disease in the elderly has become an important public health issue and a burden on the public health system [3]. Periodontitis has been considered a worldwide pandemic that

\footnotetext{
*Correspondence: pupen@naver.com; purheit@daum.net

${ }^{\dagger}$ Hyo-Geun Choi and Soo-Hwan Byun have contributed equally to this study

${ }^{1}$ Research Center of Clinical Dentistry, Hallym University Clinical Dentistry Graduate School, Chuncheon 24252, Korea

Full list of author information is available at the end of the article
}

results in reduced quality of life and disability [3]. Early studies reported that Tannerella forsythia, Actinobacillus actinomycetemcomitans, and Porphyromonas gingivalis are the primary causative agents in periodontal disease [4]. The microbial community in the oral cavity is referred to as the oral microbiota, oral microflora, or oral microbiome $[5,6]$. They are present in the oral cavity and are mainly found in dental plaque [7, 8]. Patients with chronic periodontitis have high levels of inflammatory factors, such as tumor necrosis factor- $\alpha$, interleukin-1, and interleukin-6 [9]. These inflammatory cytokines activate bone destruction by up-regulating the receptor activator of nuclear factor- $\mathrm{kB}$ ligand (RANKL) [9]. Previous studies revealed that the inhibition of RANKL could 
increase bone volume and density [10]. Based on these reports, chronic periodontitis and systemic inflammatory bone destruction could be related to the progression of osteoporosis. Bone minerals have the ability to promote inflammation and affect periodontal disease, and are considered to be an initiating factor in subsequent alveolar bone loss and disease progression [11].

Osteoporosis is considered a metabolic disease with an approximately $30 \%$ prevalence in women and $12 \%$ prevalence in men [12]. Additionally, the Nutrition and Health Survey in Taiwan (2005-2008) reported that the rates of osteoporosis for men and women older than 50 years were $23.9 \%$ and $38.3 \%$, respectively [13]. Osteoporosis is a systemic disease that decreases bone mineral density (BMD). Osteoporosis is defined as a physiological process in which patients show bone structure defects. This can cause a higher risk of bone fractures and increase bone fragility [14]. The probability of fractures for patients could increase up to approximately $40 \%$ with osteoporosis, and the loss of autonomy leads to decreased quality of life $[10,15]$. Early detection of osteoporosis may prevent fractures in patients with osteoporosis.

The BMD T-score is considered the essential standard for evaluating whether patients have osteoporosis. Femoral neck BMD was the reference standard for osteoporosis diagnosis, as assessed by dual-energy X-ray absorptiometry, using the Third National Health and Nutrition Examination Survey reference database from women aged 20-29 years [16, 17]. BMD is also the best tool for the fracture risk assessment. A 1-standard deviation decrease in BMD increases the fracture risk by 1.52.0-fold [18]. BMD is measured at several skeletal sites, but the lumbar and femoral regions are the most widely used in clinical practice $[19,20]$. Hormone changes, especially decreased estrogen levels, are related to menopause and oxidative stress and can lead to bone loss, which can cause the development of osteoporosis [21].

Although periodontal disease is believed to be a localized disease, osteoporosis is a systemic process. Nevertheless, bone loss is a common characteristic in both diseases and is affected by many factors [22]. Osteoporosis and periodontitis show cumulative rates of bone loss with aging and have some common risk factors, including smoking habits, alcohol consumption, diabetes, and socioeconomic status [23, 24]. Decreased BMD may be related to periodontal tissue destruction. Previous studies have revealed that postmenopausal women with osteoporosis are susceptible to dental plaque development. Further, a recent study reported that osteoporosis can be diagnosed with a panoramic radiograph of women with pathologic bone fractures using radiomorphometric measurements, such as the mandibular cortical index. The association between periodontitis and osteoporosis/ fractures has been documented; however, the findings remain unclear and there is no study focused on Asian or Korean individuals concerning this topic. This lack of adequate information might be due to differences in sample sizes, types of groups, and methods [25]. The aim of this study was to identify the association between periodontitis and osteoporosis and fractures using a cross-sectional study design and considering the Korean Genome and Epidemiology Study (KoGES) health examinee (HEXA) data.

\section{Materials and methods \\ Study population and data collection}

The Ethics Committee of Hallym University (201902-020) approved this study and the use of the KoGES HEXA data. All methods were carried out in accordance with relevant guidelines and regulations of the Ethics Committee of Hallym University. The requirement for written informed consent was waived by the Institutional Review Board. This cross-sectional study relied on data from the KoGES from 2004-2016. A detailed description of these data was provided in a previous study [26]. Among the KoGES Consortium, we used the KoGES HEXA data, which include information collected from urban residence participants 40 years or older. The baseline information was obtained from the 2004-2013 data were used.

\section{Participant selection}

Of 173,209 participants, we excluded those who did not have records pertaining to height or weight $(n=698)$, smoking history $(\mathrm{n}=494)$, alcohol consumption $(\mathrm{n}=1463)$, nutrition records $(\mathrm{n}=1994)$, osteoporosis history $(\mathrm{n}=101)$, and periodontitis $(\mathrm{n}=33,166)$. Finally, 9969 participants with periodontitis and 125,324 control individuals (without periodontitis) were included (Fig. 1). Then, we analyzed the osteoporosis history of all participants in the periodontitis and control groups (primary objective). Thereafter, we analyzed the history of any fractures for those in the periodontitis and control groups (secondary objective). In total, 2922 participants were excluded from both groups because of a lack of records providing information on fractures.

\section{Survey}

Trained interviewers interviewed the participants to obtain data regarding their history of periodontitis, osteoporosis, and fractures. Body mass index (BMI) was calculated as $\mathrm{kg} / \mathrm{m}^{2}$ using the health check-up data. Smoking histories were used to create the following categories: non-smoker, $<100$ cigarettes over the course of a lifetime; past smoker, quit more than 1 year ago; and current smoker [27, 28]. Alcohol consumption histories 


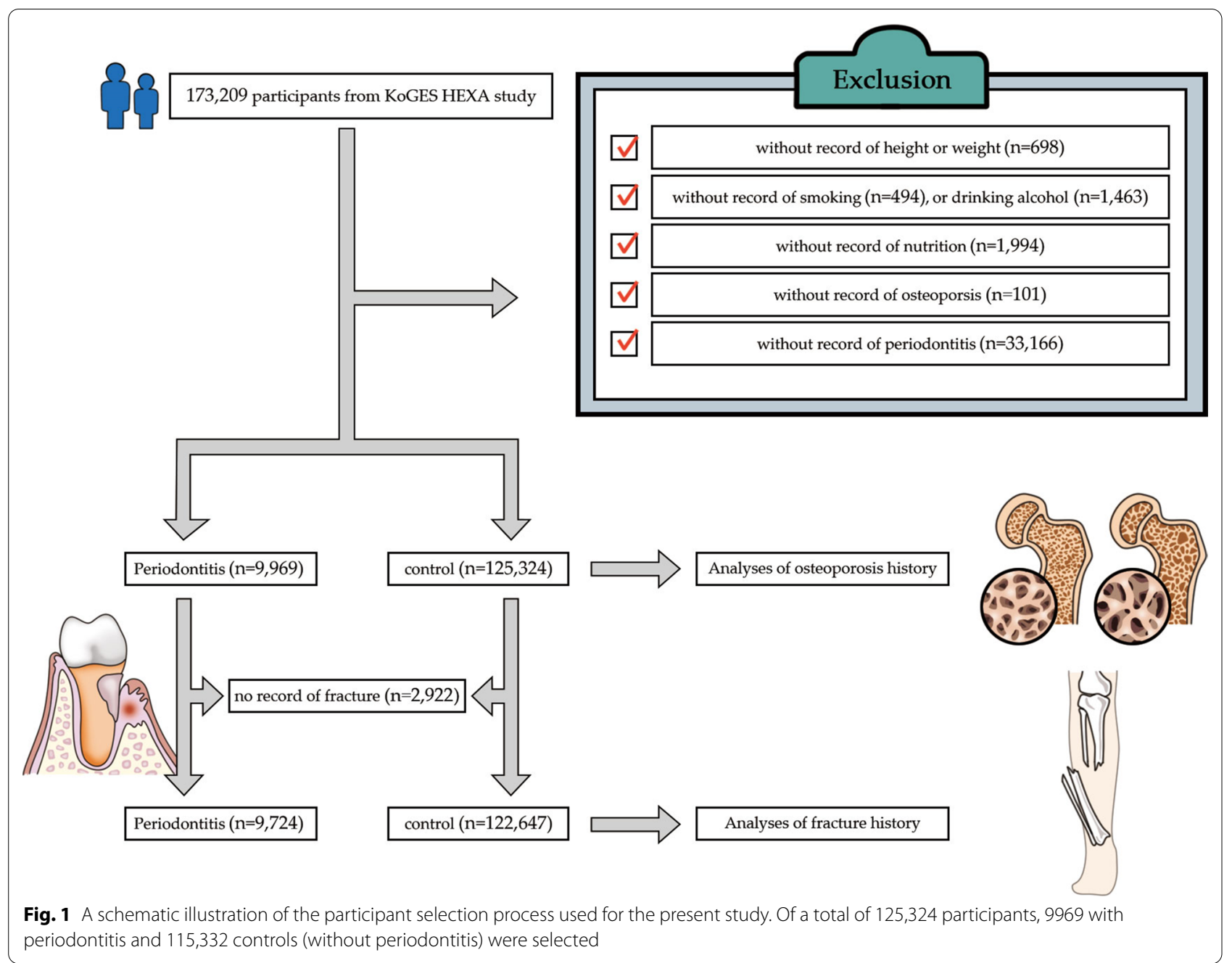

were used to create the non-drinker, past drinker, and current drinker categories. Nutritional intake (total calories $[\mathrm{kcal} /$ day], protein $[\mathrm{g} / \mathrm{day}]$, fat $[\mathrm{g} / \mathrm{day}]$, carbohydrate $[\mathrm{g} /$ day], calcium $[\mathrm{mg} / \mathrm{d}]$, phosphorus $[\mathrm{mg} / \mathrm{d}]$, and potassium $[\mathrm{mg} / \mathrm{d}]$ ) was surveyed using a food frequency questionnaire, as performed during a previous study $[29,30]$. Income groups were categorized based on the household income as non-respondent, low income (approximately $<\$ 2000$ per month), middle income (approximately \$2000-\$3999 per month), and high income (approximately $\sim \$ 4000$ or more per month).

In this study, periodontitis was set as the independent variable, whereas osteoporosis and fracture were the dependent variables.

\section{Statistical analysis}

Chi-squared tests were used to compare the roles of sex, income group, smoking, and drinking status. The independent $\mathrm{t}$-test was used to compare age, BMI, and nutritional intake. Chi-squared and t-tests were used to evaluate distributional differences in categorical and continuous variables, respectively, between the participants with and without periodontitis.

To analyze the odds ratio (OR) of periodontitis for those with osteoporosis and fractures, multiple logistic regression models were used to evaluate the association between periodontitis (exposure) and osteoporosis or the presence of fractures (outcomes). The results are presented with the crude and adjusted models for age, sex, income group, BMI, smoking, alcohol consumption, total calories, protein, fat, carbohydrate intake, calcium, phosphorous, and potassium intake. During the subgroup analyses based on age and sex, the medians were fixed at 52 years or younger and 53 years or older.

Two-tailed analyses were conducted and $P<0.05$ was considered statistically significant. The results were statistically analyzed using SPSS software (version 24.0; IBM, Armonk, NY, USA). 


\section{Results}

The general characteristics were different among participants in the periodontitis and control groups (Table 1). There were statistically significant differences in age, sex, BMI, income, smoking, alcohol consumption, total calories, fat levels, protein levels, and carbohydrate levels between the periodontitis and control groups (Table 1 ).

The adjusted OR (aOR) of periodontitis for osteoporosis was 2.16 (95\% confidence interval [CI], 2.01$2.31 ; P<0.001$ ) (Table 2). These results were consistent with the results of subgroup analyses, except for men 52 years or younger. The aORs were 1.98 (95\% CI 1.69-2.33) for women 52 years or younger, $2.68(95 \%$

Table 1 General characteristics of participants

\begin{tabular}{|c|c|c|c|}
\hline \multirow[t]{2}{*}{ Characteristics } & \multicolumn{2}{|c|}{ Total participants } & \multirow[t]{2}{*}{$P$ value } \\
\hline & Periodontitis & Control & \\
\hline Age (mean $\pm S D)$ & $54.8 \pm 7.9$ & $53.0 \pm 8.3$ & $<0.001^{*}$ \\
\hline $\operatorname{Sex}(n, \%)$ & & & $<0.001^{\dagger}$ \\
\hline Men & 3852 (38.6) & $43,409(34.6)$ & \\
\hline Women & $6117(61.4)$ & $81,915(65.4)$ & \\
\hline BMI (mean \pm SD: $\left.\mathrm{kg} / \mathrm{m}^{2}\right)$ & $24.0 \pm 2.9$ & $23.9 \pm 2.9$ & $<0.001^{*}$ \\
\hline Income $(n, \%)$ & & & $<0.001^{\dagger}$ \\
\hline Missing, no response & $766(7.7)$ & $10,854(8.7)$ & \\
\hline Lowest & 3435 (34.5) & $35,590(28.4)$ & \\
\hline Middle & 3675 (36.9) & 49,421 (39.4) & \\
\hline Highest & $2093(21.0)$ & $29,459(23.5)$ & \\
\hline Smoking status (n, \%) & & & $<0.001^{\dagger}$ \\
\hline Non-smoker & $6685(67.1)$ & $91,121(72.7)$ & \\
\hline Past smoker & $1796(18.0)$ & $18,593(14.8)$ & \\
\hline Current smoker & $1488(14.9)$ & $15,610(12.5)$ & \\
\hline $\begin{array}{l}\text { Alcohol consumption } \\
(\mathrm{n}, \%)\end{array}$ & & & $<0.001^{\dagger}$ \\
\hline Non-drinker & $4784(48.0)$ & $64,037(51.1)$ & \\
\hline Past drinker & $475(4.8)$ & $4537(3.6)$ & \\
\hline Current drinker & $4710(47.2)$ & $56,750(45.3)$ & \\
\hline \multicolumn{4}{|l|}{$\begin{array}{l}\text { Nutritional intake } \\
(\text { mean } \pm S D)\end{array}$} \\
\hline Total calories (kcal/d) & $1760.1 \pm 580.5$ & $1749.4 \pm 569.4$ & 0.073 \\
\hline Protein $(\mathrm{g} / \mathrm{d})$ & $58.9 \pm 26.6$ & $59.8 \pm 26.4$ & $0.002^{*}$ \\
\hline Fat $(g / d)$ & $27.5 \pm 18.5$ & $28.3 \pm 18.2$ & $<0.001^{*}$ \\
\hline Carbohydrate (g/d) & $315.0 \pm 95.2$ & $310.0 \pm 92.8$ & $<0.001^{*}$ \\
\hline Calcium (mg/d) & $446.3 \pm 264.2$ & $447.3 \pm 266.1$ & $0.712^{*}$ \\
\hline Phosphorus (mg/d) & $889.7 \pm 369.5$ & $896.4 \pm 367.3$ & $0.082^{*}$ \\
\hline Potassium (mg/d) & $2243.9 \pm 1095.1$ & $2253.7 \pm 1075.8$ & $0.380^{*}$ \\
\hline Osteoporosis (n, \%) & 1255 & 7867 & $<0.001^{\dagger}$ \\
\hline Fracture $(n, \%)$ & 1824 & 14,926 & $<0.001^{\dagger}$ \\
\hline
\end{tabular}

$\mathrm{SD}$, standard deviation; BMI, body mass index

* Independent $t$ test

+ Chi-squared test
CI 2.04-3.51) for men 53 years or older, and 2.12 (95\% CI 1.96-2.30) for women 53 years or older $(P<0.001$ for all).

The aOR of periodontitis for any fracture was 1.54 (95\% CI 1.46-1.62; $P<0.001$ ) (Table 3 ).

These results were consistent in all subgroups. The aORs were 1.50 (95\% CI 1.31-1.72) for men 52 years or younger, 1.65 (95\% CI 1.46-1.87) for women 52 years or younger, 1.47 (95\% CI 1.32-1.63) for men 53 years or older, and 1.54 (95\% CI 1.41-1.68) for women 53 years or older $(P<0.001$ for all $)$.

\section{Discussion}

This study was based on the hypothesis that osteoporosis and fractures are likely associated with periodontitis. Our results revealed a statistically significant association between osteoporosis and periodontitis after adjusting for sex, age, income, obesity, smoking, alcohol consumption, and nutritional intake among the participants. Because this study was based on a questionnaire-based survey, it also analyzed fractures, and both osteoporosis and fractures showed similar results. The present study can be considered reliable because analyses of two different variables resulted in consistent outcomes. Only osteoporosis in younger men showed different results compared to the other subgroups. This could be explained by the lower cases of osteoporosis observed in younger men [31-33]. There were significant differences in the other subgroups of osteoporosis and periodontitis. These results would not confirm the interaction between age and osteoporosis in both sexes because of the lower number of younger men that participated in the study.

Some studies found that low BMD was related to the loss of alveolar bone and periodontal tissue [34-36]; however, others found no such association [37-39]. The influence of oral hygiene on the relationship between BMD and periodontal disease was investigated by previous studies with varying results [40-42]. Buffalo Women's Health Initiative Observational Study demonstrated a statistically significant association between skeletal BMD and the clinical attachment level of postmenopausal women without subgingival calculus; however, no statistically significant association was found for postmenopausal women with subgingival calculus [41]. On the contrary, another study reported that participants with periodontitis who underwent regular dental care had a 1.3-fold risk of osteoporosis, but that the risk was sixfold higher for participants with periodontitis who did not undergo dental care. The study recommended regular check-ups for periodontitis patients to prevent aggravation related to osteoporosis [42]. Previous studies demonstrated that antiresorptive treatments, including hormone replacement therapy, antiresorptive agents, 
Table 2 Crude and adjusted odds ratios (95\% confidence interval) of periodontitis for osteoporosis

\begin{tabular}{|c|c|c|c|c|c|c|}
\hline \multirow[t]{2}{*}{ Characteristics } & \multirow{2}{*}{$\begin{array}{l}\text { Osteoporosis } \\
(n, \%)\end{array}$} & \multirow{2}{*}{$\begin{array}{l}\text { No osteoporosis } \\
(\mathrm{n}, \%)\end{array}$} & \multicolumn{4}{|c|}{ Odds ratios for osteoporosis } \\
\hline & & & Crude & $P$ value & Adjusted $^{\dagger}$ & $P$ value \\
\hline \multicolumn{7}{|c|}{ Total participants $(n=135,293)$} \\
\hline Periodontitis & $1255(12.6)$ & $7865(6.3)$ & $2.15(2.02-2.29)$ & $<0.001^{*}$ & $2.16(2.01-2.31)$ & $<0.001^{*}$ \\
\hline Control & $8714(87.4)$ & $117,457(93.7)$ & 1.00 & & 1.00 & \\
\hline \multicolumn{7}{|c|}{ Age $\leq 52$ years, men $(n=21,513)$} \\
\hline Periodontitis & $9(0.6)$ & $64(0.3)$ & $1.98(0.98-3.98)$ & 0.056 & $1.82(0.90-3.68)$ & 0.095 \\
\hline Control & $1242(99.4)$ & $20,016(99.4)$ & 1.00 & & 1.00 & \\
\hline \multicolumn{7}{|c|}{ Age $\leq 52$ years, women $(n=45,451)$} \\
\hline Periodontitis & $184(7.2)$ & $1457(3.4)$ & $2.21(1.88-2.59)$ & $<0.001^{*}$ & $1.98(1.69-2.33)$ & $<0.001^{*}$ \\
\hline Control & $2370(92.8)$ & $41,440(96.6)$ & 1.00 & & 1.00 & \\
\hline \multicolumn{7}{|c|}{ Age $\geq 53$ years, men $(n=25,748)$} \\
\hline Periodontitis & $69(2.9)$ & $260(1.1)$ & $2.61(1.99-3.41)$ & $<0.001^{*}$ & $2.68(2.04-3.51)$ & $<0.001^{*}$ \\
\hline Control & $2350(97.1)$ & $23,069(98.9)$ & 1.00 & & 1.00 & \\
\hline \multicolumn{7}{|c|}{ Age $\geq 53$ years, women $(n=42,581)$} \\
\hline Periodontitis & $994(27.9)$ & $6086(15.6)$ & $2.09(1.93-2.26)$ & $<0.001^{*}$ & $2.12(1.96-2.30)$ & $<0.001^{*}$ \\
\hline Control & $2570(72.1)$ & 3232 (84.4) & 1.00 & & 1.00 & \\
\hline
\end{tabular}

${ }^{\dagger}$ Models adjusted for age, sex, income group, BMl, smoking, alcohol consumption, and nutritional intake (total calories, protein, fat, carbohydrate intake, calcium, phosphorous, and potassium intake)

Crude and adjusted odds ratios ( $95 \%$ confidence interval) were calculated by using multiple logistic regression analyses

Table 3 Crude and adjusted odds ratios (95\% confidence interval) of periodontitis for fracture

\begin{tabular}{|c|c|c|c|c|c|c|}
\hline \multirow[t]{2}{*}{ Characteristics } & \multirow{2}{*}{$\begin{array}{l}\text { Fracture } \\
(n, \%)\end{array}$} & \multirow{2}{*}{$\begin{array}{l}\text { No fracture } \\
(n, \%)\end{array}$} & \multicolumn{4}{|c|}{ Odds ratios for fracture } \\
\hline & & & Crude & $P$ value & Adjusted $^{\dagger}$ & $P$ value \\
\hline \multicolumn{7}{|c|}{ Total participants $(n=132,371)$} \\
\hline Periodontitis & $1824(18.8)$ & $14,926(12.2)$ & $1.67(1.58-1.76)$ & $<0.001^{*}$ & $1.54(1.46-1.62)$ & $<0.001^{*}$ \\
\hline Control & $7900(81.2)$ & $107,721(87.8)$ & 1.00 & & 1.00 & \\
\hline \multicolumn{7}{|c|}{ Age $\leq 52$ years old, men $(n=21,126)$} \\
\hline Periodontitis & $295(21.0)$ & $2885(14.6)$ & $1.55(1.35-1.77)$ & $<0.001^{*}$ & $1.50(1.31-1.72)$ & $<0.001^{*}$ \\
\hline Control & $1112(79.0)$ & $16,834(85.4)$ & 1.00 & & 1.00 & \\
\hline \multicolumn{7}{|c|}{ Age $\leq 52$ years old, women $(n=44,739)$} \\
\hline Periodontitis & $312(12.5)$ & $3172(7.5)$ & $1.76(1.55-1.99)$ & $<0.001^{*}$ & $1.65(1.46-1.87)$ & $<0.001^{*}$ \\
\hline Control & $2189(87.5)$ & $39,066(92.5)$ & 1.00 & & 1.00 & \\
\hline \multicolumn{7}{|c|}{ Age $\geq 53$ years old, men $(n=25,149)$} \\
\hline Periodontitis & $475(20.1)$ & $3250(14.3)$ & $1.51(1.36-1.69)$ & $<0.001^{*}$ & $1.47(1.32-1.63)$ & $<0.001^{*}$ \\
\hline Control & $187(9.9)$ & $19,537(95.7)$ & 1.00 & & 1.00 & \\
\hline \multicolumn{7}{|c|}{ Age $\geq 53$ years old, women $(n=41,357)$} \\
\hline Periodontitis & $742(21.5)$ & $5619(14.8)$ & $1.57(1.44-1.71)$ & $<0.001^{*}$ & $1.54(1.41-1.68)$ & $<0.001^{*}$ \\
\hline Control & $212(78.5)$ & $32,284(85.2)$ & 1.00 & & 1.00 & \\
\hline
\end{tabular}

\footnotetext{
${ }^{\dagger}$ Models adjusted for age, sex, income group, BMl, smoking, alcohol consumption, and nutritional intake (total calories, protein, fat, carbohydrate intake, calcium, phosphorous, and potassium intake)

Crude and adjusted odds ratios ( $95 \%$ confidence interval) were calculated by using multiple logistic regression analyses
}

calcium, and vitamin D supplements, can have positive effects on the periodontal condition of postmenopausal women $[43,44]$.

The different conclusions of previous studies might have resulted from differences in the study designs, various sample sizes, and various influential factors. Most studies used a cross-sectional or retrospective design to demonstrate the association between osteoporosis and periodontitis [35-39, 44, 45]. A population-based cohort study revealed a statistically significant association 
between periodontitis and osteoporosis after adjusting for demographic characteristics [46]. However, the study did not include potential influential factors, such as systemic conditions or comorbidities. Additionally, there are very few studies on the association between osteoporosis and periodontitis in Asia, especially in Korea. Therefore, this study was performed with adjustments for many factors, analyzing both osteoporosis and fracture, with many Asian participants.

The pathophysiology between osteoporosis and periodontitis has also been explored by previous studies [47, 48], and various possible mechanisms might have been involved in the results. First, osteoporosis may induce alveolar bone loss in periodontitis [48]. Anbinder et al. suggested that periodontitis could be a risk factor for systemic bone loss, particularly for postmenopausal women [47]. Second, periodontitis is an inflammatory disease related to bacterial biofilm and immune response. Inflammatory cytokines and the subsequent immune responses are activated to protect periodontal tissue from bacterial invasion [9]. These cytokines could also contribute to the generation of osteoclasts from osteoclast progenitor cells and aggravate alveolar bone loss [9]. Monocytes induced by periodontal pathogens could induce systemic disease such as osteoporosis. Additionally, the interleukin-17/Thelper 17 pathway may be associated with RANKLinduced osteoclast formation in bone destruction. This mechanism may influence BMD [49-51].

This study used the data of a large population. Despite this advantage, there were a few limitations. First, it was impossible to include all influencing associative factors because the KoGES data did not include all confounding factors. For example, medical treatment and drug intake could be influential factors; however, they could not be included in this study. This study attempted to adjust for as many factors as possible to minimize surveillance bias. Second, the KoGES data were collected using a questionnaire survey; therefore, the accuracy of the survey used for this study could be questionable. Third, fractures may also occur because of trauma. However, the analysis of fractures did not have a great influence on this study because it was performed to complement the analysis of osteoporosis. Fourth, this was a comparative study with no evidence of a causal relationship. Fifth, it was based on a self-reported questionnaire. Self-reported questionnaires have the disadvantage of inaccuracy in diagnosis for periodontitis and osteoporosis/fracture. Therefore, this study could not present the severity and extent of periodontitis. Finally, the reliability of the questionnaires in terms of the frequency of smoking, frequency of alcohol consumption, and nutritional intake is unclear. To collect exact data, the reliability and validity of the questionnaire-based survey should be examined in future studies. However, this study provides a few meaningful results regarding periodontitis and osteoporosis and fractures. First, this study used a large sample population. Based on our investigation, this study is the largest population-based sample study of an Asian population. Second, the risk factors for osteoporosis and periodontitis increase with aging. Furthermore, women are at higher risk for osteoporosis than men, and women experiencing estrogen deficiency after menopause are at higher risk for osteoporosis [52, 53]. Additionally, obese individuals tend to have higher BMD than those with normal weight measurements [54]. This study considered nutritional intake, age, sex, obesity, income, smoking, and alcohol consumption as influential factors to evaluate the independent association between periodontitis and osteoporosis and fracture. Further studies should be conducted using a larger number of participants and with a clinician's diagnosis, by using public health insurance data.

\section{Conclusions}

This study demonstrated that osteoporosis and fractures are associated with periodontitis. Dentists and physicians should consider the possibility of interactions between osteoporosis and periodontitis. Furthermore, it is recommended that clinicians should perform examinations to determine whether the examined patients have osteoporosis and periodontitis. Additionally, regular oral hygiene and the BMD T-score examinations should be performed to prevent the aggravation of osteoporosis and periodontitis.

\section{Abbreviations}

aOR: Adjusted odds ratio; BMD: Bone mineral density; BMl: Body mass index; Cl: Confidence interval; HEXA: Health examinee; KoGES: Korean Genome and Epidemiology Study; OR: Odds ratio; RANKL: Receptor activator of nuclear factor-KB ligand; SD: Standard deviation.

\section{Acknowledgements}

We would like to thank Yoon Mi Shin for their kind help in the preparation of the figure work.

\section{Authors' contributions}

Data curation, S-HB, DMY and H-GC; Formal analysis, DMY and H-GC; Investigation, S-HB; Supervision, S-HB, B-EY and S-JH; Validation, S-HB and S-JH; Writingoriginal draft, S-HB; Writing-review and editing, S-HB, S-JK and S-JH. All authors read and approved the final manuscript.

\section{Funding}

This work was supported by the Korea Medical Device Development Fund grant funded by the Korea government (the Ministry of Science and ICT, the Ministry of Trade,Industry and Energy, the Ministry of Health \& Welfare, Republic of Korea, the Ministry of Food and Drug Safety) (Project Number: 202014X31) (Project Number: 202015X33). This research was supported by a grant of the Korea Health Technology R\&D Project through the Korea Health Industry Development Institute (KHIDI), funded by the Ministry of Health \& Welfare, Republic of Korea (Grant Number: HI20C2114). 


\section{Availability of data and materials}

The data that support the findings of this study are available from the database of Korean Genome and Epidemiology Study (KoGES) http://www.nih. go.kr/contents.es? $\mathrm{mid}=\mathrm{a} 40504010000$ but restrictions apply to the availability of these data, which were used under license for the current study, and so are not publicly available. Data are however available from the authors upon reasonable request and with permission of Korean Genome and Epidemiology Study (KoGES)

\section{Declarations}

\section{Ethics approval and consent to participate}

The Ethics Committee of Hallym University approved this study and the use of the KoGES HEXA data (2019-a02-020). All methods were carried out in accordance with relevant guidelines and regulations of the Ethics Committee of Hallym University.

\section{Consent for publication}

All authors consent publication.

\section{Competing interests}

All authors declare that they have no conflict of interest.

\section{Author details}

${ }^{1}$ Research Center of Clinical Dentistry, Hallym University Clinical Dentistry Graduate School, Chuncheon 24252, Korea. ${ }^{2}$ Department of Otorhinolaryngology-Head and Neck Surgery, Hallym University College of Medicine, Dong$\tan 18450$, Korea. ${ }^{3}$ Department of Oral and Maxillofacial Surgery, Dentistry, Hallym University College of Medicine, Anyang 14068, Korea. ${ }^{4}$ Hallym Data Science Laboratory, Hallym University College of Medicine, Anyang, Korea. ${ }^{5}$ Department of Orthopaedic Surgery, Hallym University College of Medicine, Dongtan 18450, Korea. ${ }^{6}$ Department of Otorhinolaryngology-Head and Neck Surgery, Hallym University College of Medicine, Anyang 14068, Korea.

\section{Received: 23 October 2020 Accepted: 2 March 2021}

\section{Published online: 17 March 2021}

\section{References}

1. Holmstrup P, Damgaard C, Olsen I, Klinge B, Flyvbjerg A, Nielsen $\mathrm{CH}$, Hansen PR. Comorbidity of periodontal disease: two sides of the same coin? An introduction for the clinician. J Oral Microbiol. 2017;9(1):1332710.

2. Kassebaum NJ, Smith AGC, Bernabe E, Fleming TD, Reynolds AE, Vos T, Murray CJL, Marcenes W. Collaborators GBDOH: Global, regional, and national prevalence, incidence, and disability-adjusted life years for oral conditions for 195 countries, 1990-2015: a systematic analysis for the global burden of diseases, injuries, and risk factors. J Dent Res. 2017;96(4):380-7.

3. CDC researchers find close to half of American adults have periodontitis. J Can Dent Assoc. 2012;78:c136.

4. Zambon JJ. Periodontal diseases: microbial factors. Ann Periodontol. 1996;1 (1):879-925.

5. Paster BJ, Boches SK, Galvin JL, Ericson RE, Lau CN, Levanos VA, Sahasrabudhe $A$, Dewhirst FE. Bacterial diversity in human subgingival plaque. J Bacteriol. 2001;183(12):3770-83.

6. Dewhirst FE, Chen T, Izard J, Paster BJ, Tanner AC, Yu WH, Lakshmanan A, Wade WG. The human oral microbiome. J Bacteriol. 2010;192(19):5002-17.

7. Bui FQ, Almeida-da-Silva CLC, Huynh B, Trinh A, Liu J, Woodward J, Asadi $\mathrm{H}$, Ojcius DM. Association between periodontal pathogens and systemic disease. Biomed J. 2019;42(1):27-35.

8. Byun SH, Min C, Park IS, Kim H, Kim SK, Park BJ, Choi HG, Hong SJ. Increased risk of chronic periodontitis in chronic rhinosinusitis patients: a longitudinal follow-up study using a national health-screening cohort. J Clin Med. 2020;9(4):1170.

9. Xiao W, Li S, Pacios S, Wang Y, Graves DT. Bone remodeling under pathological conditions. Front Oral Biol. 2016;18:17-27.

10. Makras P, Delaroudis S, Anastasilakis AD. Novel therapies for osteoporosis. Metabolism. 2015;64(10):1199-214.
11. Arora M, Weuve J, Schwartz J, Wright RO. Association of environmental cadmium exposure with periodontal disease in U.S. adults. Environ Health Perspect. 2009;117(5):739-44

12. Wright NC, Looker AC, Saag KG, Curtis JR, Delzell ES, Randall S, DawsonHughes $\mathrm{B}$. The recent prevalence of osteoporosis and low bone mass in the United States based on bone mineral density at the femoral neck or lumbar spine. J Bone Miner Res. 2014;29(11):2520-6.

13. Lin YC, Pan WH. Bone mineral density in adults in Taiwan: results of the Nutrition and Health Survey in Taiwan 2005-2008 (NAHSIT 2005-2008). Asia Pac J Clin Nutr. 2011;20(2):283-91.

14. Consensus development conference. prophylaxis and treatment of osteoporosis. Osteoporos Int. 1991;1(2):114-7.

15. Ethgen O, Hiligsmann M, Burlet N, Reginster JY. Public health impact and cost-effectiveness of dairy products supplemented with vitamin D in prevention of osteoporotic fractures. Arch Public Health. 2015;73:48.

16. Kanis JA, McCloskey EV, Johansson $\mathrm{H}$, Oden A, Melton $L$, Khaltaev $\mathrm{N}$. A reference standard for the description of osteoporosis. Bone. 2008:42(3):467-75

17. Leslie WD, Shevroja E, Johansson H, McCloskey EV, Harvey NC, Kanis JA, Hans D. Risk-equivalent T-score adjustment for using lumbar spine trabecular bone score (TBS): the Manitoba BMD registry. Osteoporos Int 2018;29(3):751-8.

18. Marshall $\mathrm{D}$, Johnell $\mathrm{O}$, Wedel $\mathrm{H}$. Meta-analysis of how well measures of bone mineral density predict occurrence of osteoporotic fractures. BMJ. 1996;312(7041):1254-9.

19. El Maghraoui A, Roux C. DXA scanning in clinical practice. QJM 2008;101(8):605-17.

20. Alarkawi D, Bliuc D, Nguyen TV, Eisman JA, Center JR. Contribution of lumbar spine BMD to fracture risk in individuals with T-score discordance. J Bone Miner Res. 2016;31(2):274-80.

21. Manolagas SC. The quest for osteoporosis mechanisms and rational therapies: how far we've come, how much further we need to go. J Bone Miner Res. 2018:33(3):371-85.

22. Ayed MS, Alsharif AF, Divakar DD, Jhugroo C, Alosaimi B, Mustafa M. Evaluating the possible association between systemic osteoporosis and periodontal disease progression in postmenopausal women. Dis Mon. 2019;65(6):193-215.

23. Albandar JM, Susin C, Hughes FJ. Manifestations of systemic diseases and conditions that affect the periodontal attachment apparatus: case definitions and diagnostic considerations. J Clin Periodontol. 2018;45(Suppl 20):S171-89.

24. Guiglia R, Di Fede O, Lo Russo L, Sprini D, Rini GB, Campisi G. Osteoporosis, jawbones and periodontal disease. Med Oral Patol Oral Cir Bucal. 2013;18(1):e93-99.

25. Mongkornkarn S, Suthasinekul R, Sritara C, Lertpimonchai A, Tamsailom S, Udomsak A. Significant association between skeletal bone mineral density and moderate to severe periodontitis in fair oral hygiene individuals. J Investig Clin Dent. 2019;10(4):e12441.

26. Kim Y, Han BG, KoGES Group. Cohort profile: the Korean Genome and Epidemiology Study (KoGES) consortium. Int J Epidemiol. 2017;46(4):1350.

27. Byun SH, Lee S, Kang SH, Choi HG, Hong SJ. Cross-sectional analysis of the association between periodontitis and cardiovascular disease using the Korean genome and epidemiology study data. Int J Environ Res Public Health. 2020;17(14):5237.

28. Byun SH, Min C, Hong SJ, Choi HG, Koh DH. Analysis of the relation between periodontitis and chronic gastritis/peptic ulcer: a crosssectional study using KoGES HEXA data. Int J Environ Res Public Health. 2020;17(12):4387.

29. Ahn Y, Kwon E, Shim JE, Park MK, Joo Y, Kimm K, Park C, Kim DH. Validation and reproducibility of food frequency questionnaire for Korean genome epidemiologic study. Eur J Clin Nutr. 2007;61(12):1435-41.

30. Byun $\mathrm{SH}$, Yoo DM, Lee JW, Choi HG. Analyzing the association between hyperuricemia and periodontitis: a cross-sectional study using KoGES HEXA data. Int J Environ Res Public Health. 2020;17(13):4777.

31. Pietschmann P, Rauner M, Sipos W, Kerschan-Schindl K. Osteoporosis: an age-related and gender-specific disease-a mini-review. Gerontology. 2009;55(1):3-12.

32. Wang Y, Tao Y, Hyman ME, Li J, Chen Y. Osteoporosis in china. Osteoporos Int. 2009;20(10):1651-62.

33. Kim Y, Kim JH, Cho DS. Gender difference in osteoporosis prevalence, awareness and treatment: based on the Korea national health 
and nutrition examination survey 2008-2011.J Korean Acad Nurs. 2015;45(2):293-305.

34. Payne JB, Reinhardt RA, Nummikoski PV, Patil KD. Longitudinal alveolar bone loss in postmenopausal osteoporotic/osteopenic women. Osteoporos Int. 1999;10(1):34-40.

35. Lohana M, Suragimath G, Abbayya K, Varma S, Zope S, Kale V. A study to assess and correlate osteoporosis and periodontitis in selected population of Maharashtra. J Clin Diagn Res. 2015;9(6):ZC46-50.

36. Tezal M, Wactawski-Wende J, Grossi SG, Ho AW, Dunford R, Genco RJ. The relationship between bone mineral density and periodontitis in postmenopausal women. J Periodontol. 2000;71(9):1492-8.

37. Lundstrom A, Jendle J, Stenstrom B, Toss G, Ravald N. Periodontal conditions in 70-year-old women with osteoporosis. Swed Dent J. 2001;25(3):89-96.

38. Elders PJ, Habets LL, Netelenbos JC, van der Linden LW, van der Stelt PF. The relation between periodontitis and systemic bone mass in women between 46 and 55 years of age. J Clin Periodontol. 1992;19(7):492-6.

39. Hernandez-Vigueras S, Martinez-Garriga B, Sanchez MC, Sanz M, EstrugoDevesa A, Vinuesa T, Lopez-Lopez J, Vinas M. Oral microbiota, periodontal status, and osteoporosis in postmenopausal females. J Periodontol. 2016;87(2):124-33.

40. Ronderos M, Jacobs DR, Himes JH, Pihlstrom BL. Associations of periodontal disease with femoral bone mineral density and estrogen replacement therapy: cross-sectional evaluation of US adults from NHANES III. J Clin Periodontol. 2000;27(10):778-86.

41. Brennan RM, Genco RJ, Hovey KM, Trevisan M, Wactawski-Wende J. Clinical attachment loss, systemic bone density, and subgingival calculus in postmenopausal women. J Periodontol. 2007;78(11):2104-11.

42. Huang YF, Chang CT, Liu SP, Muo CH, Tsai CH, Hong HH, Shen YF, Wu CZ The impact of oral hygiene maintenance on the association between periodontitis and osteoporosis: a nationwide population-based cross sectional study. Medicine (Baltimore). 2016;95(6):e2348.

43. Passos-Soares JS, Vianna MIP, Gomes-Filho IS, Cruz SS, Barreto ML, Adan LF, Rosing CK, Trindade SC, Cerqueira EMM, Scannapieco FA. Association between osteoporosis treatment and severe periodontitis in postmenopausal women. Menopause. 2017;24(7):789-95.

44. Penoni DC, Torres SR, Farias ML, Fernandes TM, Luiz RR, Leao AT. Association of osteoporosis and bone medication with the periodontal condition in elderly women. Osteoporos Int. 2016;27(5):1887-96.
45. Sultan N, Rao J. Association between periodontal disease and bone mineral density in postmenopausal women: a cross sectional study. Med Oral Patol Oral Cir Bucal. 2011;16(3):e440-447.

46. Lin TH, Lung CC, Su HP, Huang JY, Ko PC, Jan SR, Sun YH, Nfor ON, Tu HP, Chang CS, et al. Association between periodontal disease and osteoporosis by gender: a nationwide population-based cohort study. Medicine (Baltimore). 2015;94(7):e553.

47. Anbinder AL, Moraes RM, Lima GMG, Oliveira FE, Campos DRC, Rossoni $\mathrm{RD}$, Oliveira LD, Junqueira JC, Ma Y, Elefteriou F. Periodontal disease exacerbates systemic ovariectomy-induced bone loss in mice. Bone. 2016;83:241-7.

48. Wactawski-Wende J. Periodontal diseases and osteoporosis: association and mechanisms. Ann Periodontol. 2001;6(1):197-208.

49. Cheng WC, van Asten SD, Burns LA, Evans HG, Walter GJ, Hashim A, Hughes FJ, Taams LS. Periodontitis-associated pathogens P. gingivalis and A. actinomycetemcomitans activate human CD14(+) monocytes leading to enhanced Th17/IL-17 responses. Eur J Immunol. 2016;46(9):2211-21.

50. Zhao R. Immune regulation of bone loss by Th17 cells in oestrogendeficient osteoporosis. Eur J Clin Invest. 2013;43(11):1195-202.

51. Sato K, Suematsu A, Okamoto K, Yamaguchi A, Morishita Y, Kadono Y, Tanaka S, Kodama T, Akira S, I wakura Y, et al. Th17 functions as an osteoclastogenic helper $T$ cell subset that links $T$ cell activation and bone destruction. J Exp Med. 2006;203(12):2673-82.

52. Boling EP. Gender and osteoporosis: similarities and sex-specific differences. J Gend Specif Med. 2001;4(2):36-43.

53. Khosla S, Melton $\sqcup$ 3rd, Riggs BL. Osteoporosis: gender differences and similarities. Lupus. 1999;8(5):393-6.

54. Felson DT, Zhang Y, Hannan MT, Anderson JJ. Effects of weight and body mass index on bone mineral density in men and women: the Framingham study. J Bone Miner Res. 1993;8(5):567-73.

\section{Publisher's Note}

Springer Nature remains neutral with regard to jurisdictional claims in published maps and institutional affiliations.
Ready to submit your research? Choose BMC and benefit from:

- fast, convenient online submission

- thorough peer review by experienced researchers in your field

- rapid publication on acceptance

- support for research data, including large and complex data types

- gold Open Access which fosters wider collaboration and increased citations

- maximum visibility for your research: over $100 \mathrm{M}$ website views per year

At BMC, research is always in progress.

Learn more biomedcentral.com/submissions 